\title{
O MATERIALISMO HISTÓRICO COMO MÉTODO DE ANÁLISE: UMA VIA POSSÍVEL PARA ENTENDER A HISTÓRIA DAS MULHERES E DA MULHER NA HISTÓRIA?
}

\author{
Mara Cristine Vitorino da Silva ${ }^{1}$ \\ João Carlos da Silva ${ }^{2}$
}

\section{RESUMO}

$\mathrm{O}$ presente artigo discute a história das mulheres. Tece um panorama sobre ideologia e poder no discurso da imprensa feminina, procurando encontrar ressonâncias sobre o perfil da mulher burguesa. A proposta é suscitar uma análise conceitual e tecer uma inter-relação entre o materialismo histórico e a perspectiva de análise de linguagem do filósofo-russo, Mikhail Bakhtin. Partimos dos pressupostos da dialética materialista histórica e da análise da ideologia abordagem na qual imprimimos um enfoque discursivo, ou seja, como estas relações contraditórias, tão bem explicadas pelo materialismo histórico, estão inseridas e mostradas no discurso. Estas duas diretrizes levaram a desvendamentos de significados ideológicos presentes em enunciados discursivos da imprensa feminina. Partimos destas duas diretrizes para fazermos uma análise dos discursos da mídia feminina, observamos as novas exigências e os critérios colocados para a mulher burguesa nos anos 30, percebendo o texto, o contexto e a "intertextualidade" dos diálogos impressos. A análise possibilitou verificar a linguagem a partir dos enunciados discursivos, e a função interacional, uma particularidade humana e histórica.

Palavras-chave: Linguagem- imprensa feminina- poder- ideologia- identidade e gênero

\section{THE MATERIALISM HISTORY AS A METHOD OF ANALYSIS: ONE WAY POSSIBLE TO UNDERSTAND THE HISTORY OF WOMEN AND WOMEN IN HISTORY?}

\begin{abstract}
This article discusses the history of women. Weaves an overview of ideology and power in the discourse of women's press, trying to find resonances Profile of bourgeois woman. The proposal is to generate a conceptual analysis and weave an interrelation between historical materialism and perspective analysis of language - Russian philosopher Mikhail Bakhtin. We set out the assumptions of the historical materialist dialectic of ideology and analysis approach in which we print a discursive approach, ie how these contradictory relations, so well explained by historical materialism, are inserted and displayed in the speech. These two guidelines led to unvealing ideological meanings present in discursive statements of the women's press. We leave these two guidelines to do an analysis of the discourses of women's media , observe the new requirements and criteria posed to bourgeois woman in the '30s , realizing the text, context and "intertextuality " of the print dialog. The analysis enabled us to verify the language from the discursive statements, and interactional function, a human and historical particularity.

Keywords: language-press-female power-ideology-identity and gender
\end{abstract}




\section{Introdução}

No campo das ciências humanas, as relações de gênero, ideologia e poder partem da abordagem como mecanismo de refletir sobre as relações femininas nas esferas pública e privada, que envolvem a sociedade e, principalmente, o questionamento que a mulher fez e faz na história antiga, moderna e contemporânea. $\mathrm{O}$ assunto em tela põe à luz, fincados pelas normas do capitalismo, em seus rodapés, as angústias e as dúvidas a serem respondidas sobre o tema da mulher na época em que vivemos.

$\mathrm{O}$ crescimento das pesquisas sobre este tema, numa perspectiva historiográfica e sociológica, não deve ser entendido como simples incorporação da história das mulheres nos estudos científicos, mas compreendido no conjunto das relações sociais determinadas historicamente, ou seja, a mulher como ser social para a determinação de um perfil de classe.

Para identificarmos este processo utilizamos dois referenciais metodológicos: a marxista, que percebe o homem inscrito na história e a filosofia da linguagem, na perspectiva de Mikhail Bakhtin. Pelas analises textuais, contextuais e históricas dos estudos de linguagem, especialmente no que tange à ideologia, verificamos as relações sociais cujo norte é a visão dialógica, na qual nos inspiramos para entender uma pequena parte das relações de gênero. $O$ que nos interessa é a verificação contextual de uma história das mulheres a partir do discurso e da ideologia implícita no interior dos mesmos. Esta discussão não está ligada à uma visão ideologizante das relações de gênero, nítidas durante os movimentos feministas questionadores, principalmente os advindos das décadas de $60 \mathrm{e}$ 70, sem negar que eles foram audazes e levaram os pensamentos e as reflexões à mídia, o que propagou influencias em todo o mundo.

Discutimos o materialismo histórico como método de análise empregado para a abordagem da mulher na história. Entendemos que a utilização do método, bem como a compreensão de suas bases, foi um dos pilares para a organização do pensamento e da reflexão sobre o tema, no que tange história, ideologia e poder no processo de constituição da mulher burguesa no período em questão.

\section{A questão do gênero e sua dimensão ideológica}

$O$ termo gênero, surgido no mundo acadêmico a partir de um foco dicotômico na época dos estudos feministas, nos anos 60, generalizou-se nas diferentes conotações sobre o termo, incluindo a singularidade entre homem e mulher, as noções psicológicas, a cultura e as relações sociais, e o olhar sobre a história e o olhar sobre a arquitetura composicional do gênero textual. Entendemos que a presença da mulher, pensando-a também como um gênero no viés feminista e como agente histórico cresce tanto no campo das ciências humanas, sociais e aplicadas, como por prismas que ampliam outras áreas de investigação. Compreendemos o gênero não como sinônimo de sexo masculino ou feminino, mas como significado em uma dimensão ideológica, daquilo que se pensa, fala e escreve sobre o masculino e o feminino, e, também, como expressão das relações sociais de uma época.

Marx \& Engels (1980), em A ideologia alemã, apresenta como componentes básicos de ideologia, o sistema de pensamento, ou seja, forma de conceber o mundo que abrange seus aspectos naturais e sociais, compreendida como as relações entre os homens e sua atividade. Vejamos:

E se em toda a ideologia os homens e suas relações nos surgem invertidos, tal como acontece numa câmara escura, isto é apenas o resultado do seu processo de vida histórico, do mesmo modo que a imagem invertida dos objetos que se forma na retina é uma conseqüência 
do seu processo de vida diretamente físico. (MARX; ENGELS, 1980, p. 25).

Marina Maluf e Maria Lúcia Mott arrolam que foram as mulheres das classes abastadas as que mais absorveram o discurso da classe dominante, conforme podemos ver logo abaixo:

Embora o discurso dominante pregasse às mulheres uma norma elaborada pelas elites sobre o papel da esposa e dona de casa, e para os homens o papel de chefe de família- regras de vida que deveriam valer para toda a população - , pode-se dizer que foram sobretudo as mulheres das camadas abastadas das maiores cidades que ligaram aos seus maridos "indissolúveis laços do matrimônio" civil e religioso. E acabaram afastadas das atividades produtivas realizadas dentro de casa, usufruindo dos novos bens de consumo, e dedicando-se exclusivamente à administração da casa e aos cuidados dos filhos, sob a retaguarda de um marido provedor (MALUF;MOTT, 2002, p. 400).

É importante destacar nesse trajeto, que a história das mulheres foi impulsionada pela fase pós-feminismo e pelo avanço da historiografia. O movimento teve início na França, nos anos 80, com Michelle Perrot buscou integralizar a história das mulheres dando uma direção epistemológica. Concomitantemente, a historiadora norte-americana Joan Scott expôs preocupação similar. A relatividade da questão do gênero, levaria às interpretações sobre a diferenciação sexual, e as impossibilidades de análises por falta de subsídios teóricos e documentais, levaram a um movimento intelectual que teve ressonância, mais tarde, em todo o mundo, inclusive no Brasil
A história das mulheres apareceu como um campo definível principalmente nas últimas décadas. Apesar de enormes diferenças de recursos para ela alocados, em sua representação e em seu lugar no currículo, na posição a ela concebida pelas universidades e pelas associações disciplinares, parece não haver mais dúvida de que a história das mulheres é uma prática estabelecida em muitas partes do mundo (SCOTT, 1992, p 63 )

Para Joan Scott, a definição teórica de gênero passa por vários processos, inclusive pelo processo que se chamaria mais tarde de descontrutivismo social. A utilização de fontes de análises e dos documentos da época nos dá um eixo norteador para identificarmos alguns traços do perfil, que ora necessita ser caracterizado. Nas décadas de 20 e 30, no chamado período entre-guerras, quando o mundo assistiu os saldos positivos e negativos da industrialização, a mulher foi agente norteador. Isto porque entendemos que essas mudanças foram propagadas pelos meios de comunicação de massa, assistidas também pelas mulheres, que começavam a despontar na indústria cultural como agentes de sedução, imaginação, inspiração e, especialmente, de condução de uma nova ordem, como já dissemos.

Os anos 30 mostraram ser um marco na ruptura de um sistema encravado na sociedade brasileira. Naquela época, nos salões públicos, festas privadas e eventos sociais, as mulheres também eram a significação dessa mudança, principalmente no que diz respeito à ascensão burguesa. Nos salões, elas mostravam modelos inspirados na moda internacional, passando a demonstrar os efeitos do capitalismo e da modernização, revelando uma nova linguagem, incorporada e difundida, tanto pelo cinema emergente, 
como pelo rádio e pelos veículos de comunicação de massa ruidosos, descortinando os valores do capitalismo de consumo na sociedade brasileira.

Desde a Belle Époque dos anos 20, quando o eixo Rio-São Paulo assistiu atônito à Semana de Arte Moderna, em São Paulo, as mulheres mostravam, com os traços da ousadia nas roupas com adereços, os colares de pérolas, os bailes ao som do charleston, quando as mãos se cruzavam e descruzavam, que estavam tecendo um perfil, nos anos 30, quando a moda passa a ser influenciada pelo capitalismo internacional, demonstrando o quão forte era a ideologia que persuadia a mulher desta época.

As primeiras décadas do século $\mathrm{XX}$ foram marcadas por profundas transformações materiais. $\mathrm{O}$ trabalho servil foi substituído pelo trabalho livre através da cultura do café, que se tornaria mola propulsora da economia, prometendo importantes lucros, especialmente a São Paulo. Um breve surto industrial e a expansão das redes de comunicação (ferrovias, portos, telégrafos) produziram um grande incremento na circulação de riqueza entre as regiões Sul e Sudeste do país, o que influenciou, direta e indiretamente, o comportamento de grupos, conforme veremos posteriormente com maior profundidade.

O impulso que o capitalismo mundial alcançou, com a expansão imperialista, entre os anos 1870 a 1900, com a plena hegemonia do capitalismo industrial, atingiu o Brasil de maneira mais efetiva a partir dos anos 20, colocando-o cada vez mais em uma posição de destaque na divisão internacional do trabalho. O setor agrário foi perdendo, aos poucos, parte de sua influência para a burguesia comercial e industrial emergente, fato consolidado na década de 30 e 40 deste século.

Outro fator preponderante para este posicionamento foi o aumento da imigração, especialmente entre os anos de 1875 a 1886 , que trouxe ao Brasil grande contingente de europeus, além de uma nova força de trabalho na indústria, produzindo um clima de favorecimento da difusão dos ideais de modernidade, de liberdade e de progresso com efeitos irradiados nos pólos de expansão no período que vai da República Velha para a Nova República.

No Brasil, a sociedade urbana vivenciou a expansão da indústria têxtil, captada pela publicidade das revistas femininas. As roupas passaram a ser mais diversificadas, houve a propagação dos conselhos de beleza e comportamento, de acordo com os preceitos da época, entre outros traços e imagens impressas nos meios de comunicação de massa, fazendo com que se criasse uma ilusão da e para a mulher de uma inserção social.

Partindo desse pressuposto, entendemos que o conceito de gênero refere-se, entre outras coisas, à construção cultural e simbólica das relações entre homens e mulheres. No Ocidente, desde os gregos, passando pelos iluministas e pelas revoluções liberais, como a Revolução Francesa, em 1789, este conceito esteve vinculado à razão objetiva, ou seja, qualidade sempre atribuída ao terreno masculino. Enquanto o Oriente supervaloriza a feminilidade - e não o fato de ser mulher-sujeito, o modelo cultural brasileiro está voltado à família. Neste contexto, a mulher tem um papel fundamental e multiplicador da ideologia da época, dando o direcionamento para a formação da estrutura familiar aceitável, característica fortemente vinculada às classes sociais modernas, especialmente à da classe burguesa.

Para compreender o universo do processo social e histórico, fazendo referência à definição da terminologia em uma dinâmica de símbolos e signos, há elementos necessários para fazermos uma análise da sociedade burguesa contemporânea, cujo cerne foi estabelecido a partir da noção iluminista de sociedade. Neste aspecto, podemos relevar o fato de que na sociedade contemporânea, organizada a partir de uma lógica iluminista, a 
mulher carrega em si um processo de significação que alimenta e sustenta a estruturação social, ao mesmo tempo em que acompanha as mudanças históricas.

As primeiras décadas do século $\mathrm{XX}$, foram determinadas também por atitudes consideradas corretas. Época das academias de letras, da valorização da medicina, da higiene, dos grandes salões, dos clubes elegantes, da valorização do esporte, do espelho. $\mathrm{O}$ culto à beleza, à boa imagem, à exibição, à sedução, à elegância, aos chás entre mulheres, dos encontros contumazes, às reuniões de negócios entre os homens, tudo isso era consoante com o progresso.

Essas condições apreendidas simbolicamente, nesta época, também eram marcadas pelas grandes cerimônias beneficentes, pelas campanhas de vacinação, inserção dos remédios no cotidiano das famílias, os cuidados com a saúde, a higienização ${ }^{3}$ e um novo formato de decoração residencial, inserindo objetos que mostravam as atitudes consideradas corretas e de acordo com a nova ordem.

Acompanhando as tendências das mudanças nos costumes urbano-industriais, citamos, ainda, as grandes orquestras, o uso do chapéu, as visitas entre famílias tradicionais, os lustres de cristais em ambientes burgueses. As mulheres neste instante eram colocadas, pelas revistas e jornais da época, como agentes importantes nas campanhas sanitárias inseridas nas estratégias de propaganda como signos indispensáveis em anúncios de remédios, produzidos pela engenharia sanitária, especialmente a partir das Fundações Osvaldo Cruz e Carlos Chagas.

Nas décadas de 20/30, as mulheres começavam a despontar como agentes de sedução, imaginação, inspiração e, especialmente, de condução de uma nova ordem. Nos salões públicos, nas festas e eventos sociais, os seus os vestidos eram inspirados na moda francesa. As mais modernas utilizavam muitas franjas, ao som do charleston. As mãos se cruzam e descruzam sobre as meias coloridas de seda, ou balançam os longos colares de cristal. No alto do braço, pulseiras tipo escrava, de marfim ou serpentes de ouro. Ondulam as plumas e os leques. O cabelo a la garçon e o chapéu-touca é a febre do momento. Nas décadas de 30 a 40, a moda passa a ser influenciada pelo capitalismo internacional e, no Brasil, pela expansão da indústria têxtil e pela publicidade das revistas femininas. As roupas são mais enfeitadas, com laços, cores berrantes. Tem início o uso dos tailleurs. As saias são franzidas ou lisas e as blusas têm laços e flores, numa harmonia de cores.

As revistas femininas passam a reproduzir os modelos, que são levados às costureiras ou modistas. O cinema tem grande influência, perpetuando tipos, como Greta Garbo, Joan Crawford. Nos anos 1940, surge o Pan Cake Make-Up, pó compacto que era aplicado com água no rosto. Neste contexto é importante salientar que, no início do século $\mathrm{XX}$, o Brasil teve contato com um processo de industrialização cujas características se assemelharam com a Revolução Industrial inglesa, no século XIX. Além de mudanças de comportamentos, disseminou também um ideal de família incorporando-o aos ideais da economia política clássica, uma vez que a mulher seria multiplicadora das normas e regras que a sociedade burguesa passaria a seguir para manter o seu domínio.

A mulher pobre passa a ter a função de esposa, mãe, companheira do marido no que diz respeito à administração dos gastos da família e contribuindo com o orçamento, trabalhando em fábricas ou exercendo outras atividades fora do lar. As burguesas, por sua vez, se enclausuraram no espaço doméstico, resumindo o cotidiano à função de esposa, senhora da sociedade, educadora dos filhos e multiplicadora da moral cristã e dos costumes tradicionais e, nos tempos livres, passaram a ler, tanto livros como revistas femininas, além de se preocuparem com a beleza. No campo político foi nos anos 30 que as mulheres conquistaram vitórias importantes, como o Código Eleitoral promulgado em fevereiro de 1932, que concedeu pela primeira vez o direito de voto às mulheres. Na Constituinte de 
1934, muitas mulheres se candidataram, como Berta Lutz e Leolinda de Figueiredo Daltro, mas apenas Carlota Pereira de Morais conseguiu se eleger por São Paulo.

Em 1933, Berta Lutz, líder da Federação Brasileira pelo Progresso Feminino, publicou A nacionalidade da mulher casada, obra em que defendia os direitos jurídicos da mulher. Foi convidada pela deputada Carlota Pereira de Queirós para elaborarem em conjunto um trabalho para a Constituinte de 1934, onde defendiam a eleição da mulher e a reforma do ensino de acordo com as demandas da nova sociedade urbano-industrial. Vários artigos da Constituição de 1934 iriam de fato beneficiar a mulher, entre eles os que estabeleciam a regulamentação do trabalho feminino, a igualdade salarial e a proibição de demissão por gravidez.

Se de um lado a imprensa alimentava a imagem da mulher como "dondoca", aquelas mulheres conseguiam participar ativamente da política, abriam novas possibilidades de ativação para a mulher na sociedade, que neste momento histórico apenas previa a liberação da mulher em seu aspecto de aparência feminina para a sociedade em geral.

Para Giles Lipovetski, o boom da beleza ocorre com a Revolução Industrial, pois, até o final do século XIX, a idolatria do belo sexo se restringia a homenagens artísticas à mulher e as práticas estéticas quase não ultrapassavam os limites do rico e cultivado. No início do século XX, a imprensa feminina, o cinema, a fotografia passaram a disseminar as normas e os ideais de beleza feminina, reforçando a ordem vigente geral, conforme citação abaixo:

Com as estrelas, as manequins, as imagens de pin-up, os modelos superlativos da feminilidade saem do reino da raridade e invadem a vida cotidiana. As revistas femininas e a publicidade exaltam o uso de produtos cosméticos por todas as mulheres. Ao mesmo tempo, enceta-se uma dinâmica irresistível de industrialização e de democratização dos produtos de beleza. Desde há um século, o culto do belo ganhou dimensão social inédita: entrou na era das massas. O desenvolvimento da cultura industrial e midiática permitiu o advento de uma nova fase da história do belo sexo, sua fase mercantil e democrática (...) durante séculos, a glorificação do belo sexo foi obra dos poetas e dos artistas, e agora em diante ela é própria da imprensa, da indústria dos cinemas, da moda e dos cosméticos. (LIPOVETSKY, 2000, p. 128-129 - grifos nossos).

O capitalismo passa a moldar a imagem e o comportamento da mulher burguesa a qual seria ou deveria ser espelho para todas as mulheres em consonância com o projeto desenvolvimentista varguista. Senhoras e senhoritas eram forjadas como instrumentos de construção do ideário da nova ordem estabelecida com a revolução burguesa, principalmente por meio da educação dos filhos, da condução de suas famílias nos espaços públicos e privados, impondo comportamentos e falas no universo público, especialmente nos salões freqüentados pelas damas da sociedade cujo perfil estava articulado aos propósitos da Revolução de 1930.

Dentre os veículos de comunicação de massa, o rádio despontava, na década de 30 , como um fenômeno de ampla divulgação e não tardou que Vargas dele se apossasse como mais um instrumento de afirmação do poder, como já afirmamos em passagens anteriores. Inicialmente, regulamentou, por decreto, o uso do rádio, reservando-se o direito de concessão a empresas particulares. Em 1934, foi ao ar, a Hora do Brasil, mais tarde, Voz do Brasil, apresentada diariamente, das 19 às 20 horas, com finalidades "informativas, 
culturais e cívicas", mesclando informações e discursos políticos com música popular e apresentação de cantores de sucesso.

[...] Vulgarizamos não só as realizações do Governo, como também procuramos esclarecer a opinião pública sobre certos problemas do momento, transmitindo-lhe noções sobre o regime que a nossa carta política adaptou e sob cuja égide vivem 45 milhões de brasileiros. [...] E, assim, pelo rádio, pela imprensa e pelo cinema, estamos realizando uma obra duradoura, patriótica e sincera - cuja finalidade superior consiste justamente no ideal que todos devemos cultuar de tornar o Brasil conhecido no mundo inteiro. (NOSSO SÉCULO, "documento sonoro", 1980, p. 70).

Nessa época, pelo exemplo citado na revista Nosso Século, fica mais evidente o conceito iluminista de sociedade, que agora pode ressonar com multiplicação dos padrões de comportamento, de beleza, de moral, costumes, etc., mostrados nas revistas segmentadas para o público feminino.

Nesse contexto, a mulher burguesa, que agora passa a utilizar-se do saber e da informação, especialmente com a leitura de livros e de revistas, torna-se agente multiplicador dos ideais da revolução burguesa, que transferiu seu poderio econômico dos cafezais para os centros urbanos.

Seguindo tal idealização, esperava-se que a mulher fosse boa esposa, mãe, educadora e também responsável pela manutenção da ordem social. Para veicular este ideal de "mulher perfeita" um artifício largamente utilizado eram os anúncios publicitários nas revistas ilustradas, conforme afirmamos anteriormente. A transição da sociedade patriarcal- latifundiária para sociedade urbano-industrial, com a quebra da hegemonia agrocafeeira e a ascensão dos setores emergentes da burguesia, traz mudanças no comportamento feminino burguês. As mulheres que de alguma forma fugiam do comportamento considerado ideal pecavam duplamente: por subverter a ordem social e os padrões estabelecidos e por extrapolar sua condição de mulher submissa (ao pai, ao marido, às autoridades) e alheia aos próprios desejos". Ao analisar a mulher e a família burguesa, Maria Ângela D'Incao ressalta que:

[...] no século XIX, a sociedade brasileira sofreu uma série de transformações: a consolidação do capitalismo; o incremento de uma vida urbana que oferecia novas alternativas de convivência social; a ascensão da burguesia e o surgimento de uma nova mentalidade - burguesa reorganizadora das vivências familiares e domésticas, do tempo e das atividades femininas (D'INCAO, 2000, p. 223).

Nelson Werneck Sodré (1983) por sua vez, afirma que o processo de desenvolvimento da classe burguesa, no Brasil, tem início no final do século XIX e se fortalece nos anos 30, durante o governo de Getúlio Vargas: "Tal processo se assemelha mais aos movimentos de uma roda quadrada, que vai se tornando redonda na medida em que rola, primeiro aos tombos, abalando as estruturas, depois mais suavemente. Nossa revolução burguesa não tornou ainda redonda essa roda gigantesca." (SODRÉ, 1990, p. 30).

Com a consolidação da burguesia no poder, firmou-se no século XIX a divisão de papéis e uma rígida separação das esferas de atuação entre os gêneros. $O$ masculino na órbita pública e o feminino no âmbito privado. Restringindo-se as mulheres a esse espaço, direcionando sua educação para os papéis de esposa, mãe e educadora dos filhos, a mulher 
sofreu um assujeitamento histórico, sendo utilizada como mediadora do conservadorismo do Estado em comunhão com as diretrizes da economia política. Esta configuração fica mais clara nos segmentos mais elevados da sociedade, ou seja, nas famílias detentoras do capital, já que as mulheres pobres por sua condição social continuaram a ter a rua como espaço e foram levadas ao mercado de trabalho.Como define Michelle Perrot:

Assim, em todos os segmentos insinua-se a concepção de que o trabalho fora do ambiente doméstico era uma infração à natureza feminina e de que a presença das mulheres neste mundo constituía-se numa ameaça a sua honra. Paralelamente, nesse século, a consolidação do sistema capitalista acarretou conseqüências profundas tanto para o processo produtivo, quanto para a organização do trabalho. Trata-se de um momento de super exploração de homens e mulheres, embora de maior desvalorização da força de trabalho feminina. (PERROT;DUBBY, 1991, p. 200).

As seções de moda e beleza passam a ocupar lugar de destaque, com anúncios de exaltação da estética, do visual, fotografias de corpos, rostos perfeitos, manequins e modelos considerados ideais para a época, na perspectiva da alta-costura. A beleza feminina torna-se em espetáculo a ser admirado por toda a sociedade, disseminando um mundo de realizações, fama e sucesso permanente. O contexto econômico marcado pela indústria dos anos 30 procurava vender um universo do espetáculo, em que a beleza, os bons modos eram as palavras de ordem. As revistas femininas estavam carregadas por conteúdos que enfatizavam conselhos de belezas, mostrando os segredos e racionalização do mundo feminino. Estava nos horizontes da imprensa feminina mudar os hábitos das mulheres considerados tradicionais para os novos tempos da produção industrial, eliminando qualquer forma de preconceito e resistências em relação às possibilidades do consumo.

Apesar do discurso em favor da igualdade entre as capacidades do homem e da mulher, a imprensa da época encarregou-se de reforçar um imaginário social de assimilação dos preconceitos entre o homem e a mulher. A euforia em torno da beleza feminina e dos ares de modernidade da vida urbana produz um conjunto de ideias e de circulação de informações e recomendações, reforçando a importância dos cuidados com a estética corporal, com a saúde e com a capacidade produtiva da mulher. Os anúncios e matérias forjavam legitimar e tornar natural o mundo da sedução, o gosto pela eterna juventude, as paixões e a procura pelo consumo constante como um dever da mulher. Como considera Gilles Lipovetsky:

A imprensa feminina adquiriu um imenso poder de influência sobre as mulheres. Generalizou a paixão pela moda, favoreceu a expansão social dos produtos de beleza, contribuiu para fazer da aparência uma dimensão essencial da identidade feminina para um maior número de mulheres. No fundo, ocorre com a imprensa feminina o mesmo que ocorreu como poder político nas democracias modernas: assim como o poder público não cessou de aumentar e de penetrar na sociedade civil, no momento mesmo em que o poder moderno se apresenta como a expressão da sociedade, reforçou-se a influência da imprensa sobre as mulheres na medida em que ela se esforçou em aumentar o poder sobre a sua própria aparência. (LIPOVETSKY, 2000, p.164), 
O elogio da beleza constituiu-se como o tema gerador de todos os conteúdos da imprensa, na construção da identidade do sujeito feminino através do discurso publicitário da mídia impressa que contribuía na manutenção de papéis e espaços que deveriam ser ocupados separadamente por homens e mulheres. O corpo feminino era colocado como eixo importante na constituição da identidade feminina, na construção dos elementos que legitimariam a institucionalização da ordem desejada como a procriação, o casamento, a família, a heterossexualidade e as futilidades, como práticas naturais de uma sociedade. Esses signos eram modernamente disseminados pelo discurso midiático através da proliferação de textos e imagens que reforçaram um imaginário a ser reproduzido pelo cotidiano feminino.

As mercadorias destinadas ao público feminino eram apresentadas como promessas de uma vida organizada de acordo com o nível intelectual da cada mulher. Neste sentido o feminino aparece reduzido ao mundo doméstico (eletrodomésticos, produtos de limpeza, móveis), sedução (moda, cosméticos, mercado de sexo, romance, amor), a reprodução (filhos e maternidade). Estava em jogo um atraente mercado publicitário que envolvia grandes quantias em dinheiro. Um nicho de mercado publicitário, envolvendo reportagens especiais, conselhos, dicas, receitas e segredos da vida moderna.

Em geral, as revistas anunciavam um universo do sucesso, de confiança no futuro de empreendedorismo. O público-alvo era a mulher de classe média, de cor branca, jovem, com um certo grau de instrução. As capas das revistas Fon-Fon e Feminina, apresentam imagens que remontavam aos perfis de moda, de beleza, da maternidade, estimulando a leitura das matérias ali apresentadas. As matérias delineavam uma nova mulher com características comuns aos ideais de modernização impostos pela sociedade de consumo, que tinha na mulher um de seus principais eixos.

As reportagens ressaltam valores que tratam das relações, emoção e cuidados para um bom relacionamento no amor. A publicidade aponta para a beleza possível, livre das barrigas, da flacidez, tudo para garantir uma boa modelagem do corpo, que reforçam os conteúdos das matérias. A Revista Feminina apresenta uma nova mulher, transformada, a ser imitada, higiênica, delicada, atual, bem informada com os acontecimentos do seu tempo, inclusive com o mundo político, colocando Getúlio Vargas como referência principal de homem público. Os anúncios mostram os produtos com poder revolucionário nos mais diferentes tratamentos da pele. As diferenças entre homens e mulheres também são apresentadas, com dicas consideradas importantes de como o homem deve tratar uma mulher. Ora o homem é apresentado como uma autoridade, ora como alguém perigoso. As mulheres são encorajadas a seguir regimes, fazer ginásticas e conservar a pele, tudo para transmitir encanto.

Entre os anos de 1920 e 1930 a imprensa feminina teve uma grande influência sobre as mulheres, favorecendo a disseminação dos produtos de beleza ao maior número possível de consumidoras. A beleza é colocada como possibilidade para todas, deixando de ser mais um privilégio de um pequeno número de mulheres. Pela ótica difundida pelas revistas especializadas, a mulher passaria a ter acesso às regalias proporcionadas pela sociedade urbano-industrial. Paralelo a isto, buscava-se a valorização da individualidade e da personalidade feminina, como requisitos importantes para a sociedade da época, tornando a elegância mais acessível e símbolo da liberdade. Nunca, até então, a beleza esteve tão associada ao sucesso à riqueza e à realização individual.

As revistas femininas desempenhavam uma importante função na constituição do ideal da mulher burguesa. A família, que tinha na mulher seu alicerce emocional, era 
um dos símbolos da burguesia urbano-industrial, que, assim como em outras épocas utilizava a moral cristã como preceito de sustentação.

Por considerarmos o fator sociológico elementar para a execução de uma análise melhor aprimorada no que tange aos papéis dos gêneros, utilizamos a filosofia da linguagem para adentrar num universo histórico e a partir dele entender um processo de formação do perfil da mulher burguesa. A partir dos enunciados discursivos de revistas, que entra num outro recorte de gênero jornalístico, encontramos traços do perfil da mulher embutidos na realidade de uma determinada época.

Partindo da teoria marxista de que o sistema econômico e social está também alicerçado nas relações privadas, procuramos verificar os enunciados como sendo resultantes da naturalização de comportamentos a partir da expressão ideológica, em que a divisão de classes distingue trabalho material do trabalho intelectual, formando um sustentáculo a partir dos enunciados discursivos da imprensa brasileira dos anos 30 , ou seja, de um lado a força produtiva e, de outra, os que pensam.

Estas ponderações nos levaram a constatar, a partir de leituras, que, no processo de sedimentação de uma classe emergente, há contrapartida ao regime vigente, especialmente no que diz respeito às mulheres burguesas, ao lado da religião, das artes, da escola, da ciência, dos maneirismos, das leis, entre outros, que passam também a ser agentes moldadores uma consciência social.

Para estudar a mulher na história consideramos a perspectiva marxista que toma o indivíduo como expressão das relações sociais, ou seja, do processo da vida real conforme Marx (1980, p.25). No capitalismo, sedimentado pelas regras da economia política, este direcionamento conduz ao processo de objetivação e ao alheamento do indivíduo. Nesse aspecto, revela-se a necessidade de uma reflexão do fenômeno a partir de uma análise social da linguagem, na qual também se incluem as relações homem e mulher na sociedade.

O Materialismo histórico como método no estudo do gênero

O método de Marx constitui um tema de relevância especial para o desenvolvimento da teoria marxista. Bottomore (1983), no Dicionário do Pensamento Marxista, considera que o materialismo dialético caracteriza-se como filosofia do marxismo, enquanto $o$ materialismo histórico é definido como a ciência marxista. Marx, ao desenvolver sua concepção materialista da história, enfatizou que o modo pelo qual a produção material de uma sociedade é realizada, constitui o fator determinante da organização política e das representações intelectuais de uma época. Assim, a base material ou econômica constitui a "infra-estrutura" da sociedade exercendo influência direta na superestrutura, ou seja, nas instituições jurídicas, políticas, leis, Estado e no plano ideológico (artes, religião, moral).

Em A Ideologia Alemã Marx (1846, p.18) formula sua concepção materialista, estabelecendo relações existentes entre as representações (a ideologia) e as condições materiais da existência ao considerar que o primeiro ato histórico é a produção dos meios que permitam a satisfação das necessidades vitais do homem, ou seja, a produção da própria vida. Neste sentido, os homens são produtores de suas representações, de suas ideias, os homens reais e ativos, tal como se acham condicionados pelo desenvolvimento das forças produtivas e pelo intercâmbio das mesmas até chegar às suas formações mais amplas. Marx e Engels (1980, p.55) explicam este processo com a clássica passagem:

Os pensamentos da classe dominante são também, em todas as épocas, os pensamentos dominantes, ou seja, a classe que tem o poder material dominante numa dada sociedade é também a potência dominante 'espiritual'. A classe que dispõe dos meios de produção material dispõe igualmente dos meios de produção intelectual, de tal modo que o 
pensamento daqueles a quem é recusado os meios de produção intelectual estão submetidos igualmente à classe dominante. Os pensamentos dominantes são apenas a expressão ideal das relações material dominantes concebida sob a forma de ideias e, portanto, a expressão das relações que fazem de uma classe a classe dominante; dizendo de outro modo, são as ideias de seu domínio.

No Manifesto do Partido Comunista (1848) é reafirmado o caráter economicista da classe burguesa: "[...] os meios de produção e de troca, sobre cuja base se ergue a burguesia, foram gerados no seio da sociedade feudal". No prefácio da "Para a Crítica da Economia Política" (1859) temos as "leis mais gerais do materialismo histórico", quando Marx já acumulava uma série de estudos em torno das ideias da economia política clássica, ao formular os eixos centrais do materialismo histórico reiterando que a base material deve ser o primeiro pressuposto a ser levado em consideração na análise de uma sociedade: "[...] O modo de produção da vida material condiciona o processo em geral de vida social, político e espiritual. Não é a consciência que determina o seu ser, mas, ao contrário, é o seu ser social que determina a sua consciência" (MARX; ENGELS, 1980, p.136). Nos séculos XVIII e XIX, desenvolveu-se antigo ideário iluminista, isto é, o entendimento de que a razão e as ideias governam o mundo. As ideias e a vontade dos indivíduos eram entendidas como fatores decisivos nas mudanças sociais ao longo da história. No século XX, a historiografia ganha uma nova dinâmica, com a coexistência de diferentes posições metodológicas.

O método materialista histórico-dialético, criado e formulado por Marx, tem se mostrado um instrumento valioso para analisar os acontecimentos históricos, sem contudo deixarmos de entender que o seu método não previa a posição e o papel ocupados pela mulher na sociedade. È com o sentido do materialismo histórico que ele se constitui referência de muita relevância para o desenvolvimento do nosso estudo.

No Dicionário do Pensamento Marxista, define-se o materialismo como tudo aquilo que depende da matéria ${ }^{4}$. Neste prisma, o materialismo é a base de toda existência dos homens, sobretudo a partir do processo de trabalho no desenvolvimento da história humana (BOTTOMORE, 1983, p. 254). A concepção materialista da história é considerada como uma descoberta científica de Marx, ao lado da teoria da mais-valia, a qual estamos citando apenas para efeito de esclarecimento, sem no momento, nela nos determos.

O modo pelo qual a produção material de uma sociedade é realizada, constitui o fator determinante da organização política e das representações intelectuais de uma época. Os principais significados filosóficos da concepção materialista da história são: negação da autonomia das ideias na vida social, afirmação do compromisso metodológico com a pesquisa historiográfica concreta - em oposição à reflexão abstrata -, centralidade da práxis humana na produção e reprodução da vida social, ênfase no trabalho enquanto processo de transformação da natureza e mediação das relações sociais. Assim, a base material ou econômica constitui a "infra-estrutura" da sociedade exercendo influência direta na superestrutura, ou seja, nas instituições jurídicas, políticas, legais, no Estado e no plano ideológico, plano que tentamos desvelar a partir da análise da constituição da classe burguesa e da significação das relações de gênero também a partir dos enunciados discursivos.

Os pontos de partida do marxismo são a dialética de Hegel, a filosofia materialista dos socialistas utópicos e as teorias econômicas dos ingleses Adam Smith e David Ricardo.

Mais do que uma filosofia, o marxismo é a crítica radical da filosofia, principalmente do sistema filosófico idealista de Hegel. Enquanto, para Hegel, a realidade se faz filosofia, para Marx a filosofia precisa incidir sobre a realidade. 
O núcleo do pensamento de Marx é sua interpretação do homem, que começa com a necessidade humana. A história se inicia com o próprio homem que, na busca da satisfação de necessidades, relaciona-se com a natureza. Para Marx, a linguagem é a mediação entre o indivíduo e a natureza e a maneira como as imagens caóticas são operadas e internalizadas, a partir do processo de significação social, é parte da integração humana.

O processo histórico no qual o homem está inserido, na visão marxista, segue um trajeto dos chamados atos históricos da vida material, necessários à construção social. Neste processo, o ser humano precisa ter condições materiais de vida para realizar as necessidades para ter uma vida de qualidade.Em primeiro lugar, precisa suprir as necessidades básicas, como comer, beber, morar e vestir. Em segundo, gerar novas necessidades a partir das necessidades satisfeitas. Em terceiro, ocorre a reprodução, ou seja, a construção da família. O quarto ato histórico seria a construção da vida material, implicações em que, ao nosso ver, a mulher passa também a ser agente essencial, que durante o processo da História vai adquirindo consciência do seu papel social.

Somente agora, depois de já termos observado quatro momentos, quatro aspectos das relações sociais originárias, achamos que o homem também tem consciência. Mas também isso não de antemão, como consciência pura. O espírito tem em si de antemão a maldição de ter sido afetado pela matéria, que aqui se faz presente na forma de camadas de ar em movimento, de sons, em suma de linguagens. A linguagem é tão velha quanto a consciência--- A linguagem é a consciência efetiva prática também existente para outros homens, portanto também existente primeiro para mim mesmo e assim como a consciência, a linguagem surge com a necessidade (grifos nossos) (MARX, 1980, p. 196-197).

A análise marxista, por sua vez, pressupõe que este processo se constitua de uma construção humana e social, que está alicerçada no modelo capitalista-iluminista, no qual a linguagem é carregada de sentidos e serve de instrumento para perpetuação e sustentação do sistema funcionalista de sociedade.

Esta sociedade "mutante" pode ser analisada por um prisma histórico, mas é necessário romper com conceitos que não avaliem a pós-modernidade e dentro desta pósmodernidade, a sociedade da informação, as tecnologias de ponta, a revolução na genética, a política, a arte, a religião, entre outros fatores, que estão inseridos nas relações, que alimenta o conjunto de significações e ressignificações, compondo as instituições, préconcebidas pelos símbolos, mitos e imagens que formam o ser social. Essas significações e ressignificações se estabelecem em relação dialógica com a sociedade.

As significações e ressignificações, que estabelecem uma relação dialógica com a sociedade, permitem entender o mecanismo de interação pessoal, a qual estendemos para a comunicação social, tendo em vista que corroboramos com Bakhtin quando o mesmo define interação, isto é, algo que não é somente um processo harmônico, mas também de embate, se pensarmos na produção dos discursos, sejam eles orais ou escritos, que circulam na sociedade. Por isso, o presente trabalho se propõe a dois desafios: o primeiro, refere-se à apropriação do método do materialismo histórico, a partir das formulações de Marx e Engels, e, o segundo, à confrontação deste método com a análise da linguagem na sociedade por meio do recorte dos enunciados discursivos da imprensa feminina.

Ao buscar a análise dos enunciados discursivos, fizemos uma leitura de Marxismo e Filosofia da Linguagem escrito Bakhtin. Esta leitura possibilitou o estabelecimento das devidas relações entre linguagem e sociedade e, principalmente, a verificação das relações 
entre a infra-estrutura e a superestrutura pela perspectiva da linguagem. Após entendermos o contexto histórico dos anos 30 e a imprensa feminina, retomamos os enunciados e a análise discursiva para compreendermos o seu caráter dialético, a ideologia e o poder inscritos no discurso.

$\mathrm{O}$ interesse foi refletir sobre a ideologia inscrita no discurso a partir da filosofia da linguagem, assunto que está estreitamente ligado ao significado de filosofia, que segundo Marilena Chauí:

É a maneira de manifestar e exprimir os problemas e as questões que, em cada época de uma sociedade, os homens colocam para si mesmos, diante do que é novo e ainda não foi compreendido. A filosofia procura enfrentar essa novidade, enfrentando caminhos, respostas e, sobretudo, propondo novas perguntas, num diálogo permanente com a sociedade e com a cultura de seu tempo, do qual ela faz parte (1984, p 43).

A proposta de Bakhtin na análise da linguagem fundamentada na teoria do estudo dos signos semióticos e, a partir desta ótica, o cumprimento da função da linguagem, desvela uma particularidade humana e histórica: o uso da linguagem e a ideologia nela inscrita. Em síntese, há uma inter-relação de signos na comunicação social, a qual necessita do contexto histórico para ser refletida de uma maneira mais densa, pois entendemos que a linguagem está carregada por significados sócio-historicamente construídos, e, como considera Bakhtin: "[...] todo signo é ideológico, e portanto também o signo lingüístico, vê-se marcado pelo horizonte social de uma época e de um grupo social determinados". (BAKHTIN, 2002, p. 44).

Pensando no signo enquanto signo linguístico, texto, enunciado, imagem, circunstanciado e circunscrito na e pela sociedade, podemos dizer que a figura da mulher na sociedade é um signo em constante reconfiguração.

Nos anos 30, período de ascensão da classe burguesa, a mulher foi peça fundamental no bojo dos embates desta revolução, formando um contingente humano decisivo, que fazia parte dos interesses emergentes de uma classe em sedimentação. No instante em que se desenvolve e consolida a ordem social burguesa, no Brasil, a mulher absorve o ideário burguês com traços peculiares próprios da cultura brasileira.

As transformações econômicas, sociais e políticas, nas primeiras décadas do século XX, impuseram novos comportamentos, nova moda, novos costumes, por conta da industrialização a partir de 1930, como já dissemos anteriormente. Junto a isto, estão também contribuições epistemológicas importantes, as quais evoluíram e/ou se transformaram concomitantemente com esta nova mulher mas que, ao mesmo tempo, deixaram lacunas, que atualmente buscam ser preenchidas com o estudo sobre gênero, cuja ênfase se estabelecesse no caráter social e historiográfico ${ }^{5}$.

Marx adotou a dialética hegeliana e substituiu o devir das ideias, ou do espírito humano, pelo progresso material e econômico. A natureza, a vida e a consciência se constituem de matéria em movimento e evolução permanente, e o materialismo histórico, para o qual o fator econômico é base e causa determinante dos fenômenos históricos e sociais, inclusive no que diz respeito às instituições jurídicas e políticas, a moralidade, a religião, as artes e a educação, é uma forma de analisar o ser social. Porém, para o propósito do nosso estudo, apenas analisar o ser social esta teoria não foi suficiente. Há uma necessidade constante de aprimorar as análises e uma delas é via filosofia da linguagem.

No marxismo, as mudanças históricas não devem ser analisadas de maneira isolada, mas sim como parte de uma totalidade. Os conceitos históricos são determinados 
pelas condições materiais da sociedade, que, em última instância, determinam os processos político, cultural, ideológico, educacional e jurídico. Portanto, a base econômica é a produção econômica e sobre ela ergue-se uma superestrutura, constituída pela organização política, moral, filosófica e jurídica. A análise das classes sociais também se coloca como elemento fundamental no conjunto da concepção materialista, cujo papel histórico a ser desempenhado determina a consciência ou visão de mundo dos seus membros ${ }^{6}$. Para MARX:

[...] Na produção social da própria vida, os homens contraem relações determinadas, necessárias e independentes de sua vontade, relações de produção estas que correspondem a uma etapa determinada de desenvolvimento de suas forças produtivas materiais. A totalidade dessas relações de produção forma a estrutura econômica da sociedade, a base real sobre a qual se levanta uma superestrutura jurídica e política, e à qual correspondem formas sociais determinadas de consciência. $\underline{O}$ modo de produção da vida material condiciona o processo em geral de vida social, política e espiritual. Não é a consciência dos homens que determina o seu ser, mas ao contrário, é o seu ser social que determina a consciência. Em uma certa etapa de seu desenvolvimento, as forças produtivas da sociedade entram em contradição com as relações de produção existentes ou, o que nada mais é do que a sua expressão jurídica, com as relações de propriedade dentro das quais aquelas até então tinham se movido. (grifos nossos) (MARX;ENGELS, 2000, p. 52).

Marx afirmou a existência de uma constante interação e interdependência entre a infra-estrutura e a superestrutura, embora, em última instância, os fatores econômicos sejam os determinantes. A presença da dialética no materialismo histórico considera que a história deve ser entendida não como um movimento circular, como mera repetição daquilo que ocorreu, mas como um movimento ascendente, que tem um início, um desenvolvimento, um ápice e uma fase de decadência. Este método parte de três premissas básicas: tudo se transforma, tudo se relaciona e as contradições são as forças motrizes da transformação.

As crises econômicas do capitalismo nada mais são do que este movimento de transformação no qual a propriedade privada dos meios de produção entra em contradição com o caráter social do processo de produção (BOTTOMORE,1988, p.104).

A totalidade histórica e a contradição são princípios centrais ao método empregado para explicar o desenvolvimento histórico do capitalismo. Portanto, existe uma vinculação estrita entre totalidade e a realidade histórica ao considerarmos que os fatos são interdependentes. A mediação, outra categoria central da dialética, refere-se ao papel do homem como mediador das relações sociais, marcadamente complexas. Em contraposição a esta visão do homem como mediador, a teoria bakhtiniana percebe que a mediação humana das relações sociais acontece por meio dos discursos produzidos na e pela sociedade.

A dialética, que percebe a história a partir de um processo e, especialmente, do seu contínuo movimento, nos deu o direcionamento intelectual para verificar as relações entre a história e a linguagem, a construção identitária e todo o seu percurso. Já a filosofia da linguagem nos fez entender melhor a ideologia e o poder inscritos no discurso e como estes são determinantes para a construção de um perfil

Tomando como base estes pressupostos teórico-metodológicos marxistas, a análise sobre a questão desta mulher específica deve ser buscada no interior das relações burguesas que lutavam, nos anos 30 no Brasil, para a consolidação de suas instituições. E, 
portanto para a concepção de sociedade do ideário burguês, visando ao fortalecimento do modelo nacional-desenvolvimentista.

Por conta do processo de modernização, a imprensa feminina, especialmente as revistas veiculavam enunciados ideologicamente comprometidos com a visão burguesa no que diz respeito à educação, à conduta moral, à família e à função da mulher neste processo. Elas inserem-se no período marcado pelo processo de modernização das formas de produção, intensificaram-se as diferenças entre as classes sociais: a classe operária, responsável pela força de trabalho no processo produtivo, a classe média emergente e a classe burguesa, detentora do capital e entrelaçada aos ideais propostos pelo Estado.

É neste cenário que temos uma importante distinção também do espaço masculino e feminino: o gênero é redimensionado nas relações sociais que emergem baseado nas diferenças percebidas entre os sexos, perpassando pelas relações de poder. Estes mecanismos podem ser percebidos em vários momentos, inclusive no que Bakhtin toma por situação e auditório. Diz ele: "A situação e o auditório obrigam o discurso interior a realizar-se em uma expressão exterior definida, que se insere diretamente no contexto não verbalizado da vida corrente". (Bakhtin, 2002, p125).

Numa nova dinâmica do olhar, a ideologia no e do discurso passa a ter um papel fundamental para a vigência do sistema econômico, pois é também por meio dela, que se difunde a força motriz da economia política, de que o trabalho é a essência da riqueza, levando o homem ao acúmulo particular e a prosperidade coletiva. Portanto, organizar uma nova sociedade passou necessariamente por estas normas, que utilizaram o discurso como mecanismo, visando atender a uma perspectiva de vida burguesa da sociedade emergente, na qual a mulher é elemento primordial, condutora de famílias, educadora, construtora de perfis, captando a ideologia do discurso e propagando-a para o estabelecimento da classe em ascensão.

O confronto entre a noção de ideologia pelo viés do materialismo histórico, em que a produção das ideias, das representações, da consciência está, á primeira vista, diretamente associada à atividade e ao comércio materiais do homem, sendo a linguagem da vida real e da filosofia da linguagem, que a ideologia está inscrita no discurso e a partir do discurso o homem se forma foi o desafio do trabalho. Em vez de pensarmos que os homens são produtores de suas representações, de suas ideias a partir das relações superestruturais, passamos a pensar no discurso, que também é produto destas relações, mas de uma forma mais ampla.

\section{Referências}

BAKHTIN, Mikhail. Marxismo e Filosofia da Linguagem: problemas fundamentais do método sócio-lógico na ciência da linguagem. São Paulo: Hucitec, 2002.

Estética da Criação Verbal. São Paulo: Martins Fontes, 1992.

BOTTOMORE, Tom. Dicionário do pensamento marxista. RJ: Zahar, 1988.

CHAUI, Marilena. O que é ideologia. São Paulo: Brasiliense, 1984.

D'INCAO, Maria Ângela. Mulher e família burguesa. In: HISTÓRIA DAS MULHERES

NO BRASIL, org. de Mary Del Priore, 5.ed. São Paulo, Ed. UNESP/Contexto/FAPESP, 2001.

LIPOVETSKY, Gilles. A terceira mulher: permanência e revolução do feminino. São Paulo: Companhia da Letras, 2000. 
SILVA, Mara Cristine Vitorino e. Ideologia e poder nos enunciados discursivos nas revistas femininas: um perfil da mulher burguesa (1930-1937). Dissertação de Mestrado. Programa de Pós-graduação em Letras. UNIOESTE, Cascavel, 2005.

MARX \& ENGELS. A ideologia alemã. Tradução Conceição Jardim e Eduardo Lúcio Nogueira. São Paulo: Martins Fontes, 1980. (V. I e II )

port., São Paulo: Abril, 2000.

Para a crítica da economia política. (Os Pensadores). Trad.

MALUF, Marina; MOTT, Maria Lúcia. Recônditos do Mundo Feminino in. SEVCENKO, Nicolau (org.) História da vida privada: República: da Belle Époque à Era do Rádio. Vol. 3. São Paulo: Companhia das Letras, 1998.

NOSSO SÉCULO. 1900/1946. Vários compositores. Direção artística: José Ramos Neto. Narração: Sérgio Viott. São Paulo: Abril Cultural,: 1980. (disco)

PERROT, Michelle \& DUBY, Georges. História das Mulheres: do Renascimento à Idade Moderna, v.3. Edições Afrontamentos, 1991. (Vol. 3)

SCOTT, Joan. História das Mulheres. In: BURKE, Peter (org.); A escrita da história: novas perspectivas.São Paulo: Editora da Universidade Estadual Paulista., 1992. p. 63-95

SODRÉ, Nelson Werneck. Capitalismo e revolução burguesa no Brasil. Belo Horizonte, Oficina de Livros, 1990.

\section{Notas}

1 Doutoranda em Língua e Cultura pela Universidade Federal da Bahia (UFBA). E-mail: maravitorino@hotmail.com

${ }^{2}$ Doutor em Filosofia, História e Educação/FE-UNICAMP. Professor do curso de Pedagogia e do Programa de Pós-graduação/Mestrado em Educação da UNIOESTE, Campus de Cascavel. Membro do grupo de pesquisa HISTEDOPR, História, sociedade e educação - Oeste do Paraná. E-mail: jcsilva05 @ terra.com.br

${ }^{3} \mathrm{Na}$ questão higiene, por exemplo, tornava-se comum o uso dos bidets nos banheiros das residências mais elegantes.

${ }^{4}$ Sobre isso, ver BOTTOMORE, Tom. Dicionário do pensamento marxista. p. 254.

${ }^{6}$ BOTTOMORE. T. Op.cit. p. 269. 